Foley Finnan, A, Gibbs, C, Waite, M and Davison-Fischer, J

Students as Producers: The Postgraduate Teaching Assistant Pilot Project.

Foley Finnan, A, Gibbs, C, Waite, M and Davison-Fischer, J (2015) Students as Producers: The Postgraduate Teaching Assistant Pilot Project. Journal of Educational Innovation, Partnership and Change, 1 (1)

This version is available: https://radar.brookes.ac.uk/radar/items/3afe24db-ae5d-4e7d-9af5-8ebe2081926e/1/

Available on RADAR: April 2016

Copyright (C) and Moral Rights are retained by the author(s) and/ or other copyright owners. A copy can be downloaded for personal non-commercial research or study, without prior permission or charge. This item cannot be reproduced or quoted extensively from without first obtaining permission in writing from the copyright holder(s). The content must not be changed in any way or sold commercially in any format or medium without the formal permission of the copyright holders.

This document is the published version of the journal article. 


\title{
Students as Producers: The Postgraduate Teaching Assistant Pilot Project
}

Ann Foley Finnan, Claire Louise Gibbs, Marion Waite, Jan Davison-Fischer Oxford Brookes University

\begin{abstract}
This paper reports on a pilot project in which two postgraduate students were supported to function in the role of teaching assistants (TAs) as part of their learning experience. The project embraced the notion of students as producers rather than consumers. Using a reflective approach, this case study was jointly written by the TAs and their teaching staff. It incorporates feedback from other students collected through an anonymous module feedback survey, which was analysed by attribution to themes. The role of TAs benefited others: students, staff and the TAs themselves. The project is a strong affirmation of the principle of treating students as producers. The impact of the role on both the students undertaking the TA role and on the tutors was profound and student experience was enhanced as a result. TAs can assist in bridging student-teacher communication gaps and support students' learning through sharing their knowledge by creating resources. This article is written from the perspectives of both the TAs and the tutors.
\end{abstract}

\section{Keywords}

Student as Producer, Teaching Assistant, Postgraduate Education, Nursing Education, Pilot Project, New Forms of Curriculum Delivery, reflection

\section{Introduction}

The Faculty of Health and Life Science at Oxford Brookes University offers a range of continuing professional development (CPD) postgraduate programmes in online distance learning mode. One example is the MSc in Nursing Studies.

\section{Rationale and perspectives}

The purpose of this case study is to provide an evaluation of a pilot project in which two learners from the MSc in Nursing Studies took on the role of online teaching assistants (TAs) for one semester. The case study is written collaboratively by the two members of the course team and the TAs. This reflects joint perspectives and evaluation of the experience and concludes with learner recommendations for future practice and research.

The overall rationale for the 'Students as TAs' initiative is improvement of what has been termed 'social and cognitive presence' (Miyzoe and Anderson, 2013), to ensure continuous currency and constructive alignment of the curriculum, to maximise the benefits of the TA, to draw upon their personal, professional and practice-based knowledge, to utilise their personal strategies for engagement with distance learning and to offer the TAs themselves a professional development opportunity.

\section{Student as producer}

Online distance learning is a rapidly expanding area of higher education provision (Briggs, 2013) and so it could be legitimately argued that valuing the student experience within online distance learning is timely and imperative. Developing learners as teaching assistants is a 


\section{Case Studies}

response to this and fits very well with a teaching philosophy that embraces the notion of student as producer rather than consumer (Neary \& Winn, 2009). The perspective draws upon earlier work undertaken within Oxford Brookes University in The Re-invention Centre for Undergraduate Research. Within this context, the focus is on the postgraduate part-time student who is studying remotely. Locally, initiatives to enhance the student experience are important in terms of informing an update of internal policy, Strategy for Enhancing the Student Experience (SESE 2), (Oxford Brookes University, 2014).

\section{The Student as TA initiative}

The intervention is a pilot project, which was offered to a small sample of students who had successfully completed several of the modules within the programme. Two students were identified to take on the role of TA, each within one of two core modules from the MSc Nursing Studies programme over the duration of one semester.

The course leader for the MSc Nursing Studies worked with each individual student to develop an independent learning contract, which included individualised learning outcomes and identification of necessary learning resources, activities and specific outputs. This also coincided with University accreditation of the postgraduate associate teachers course as an Open Online Course (OOC), First Steps into Teaching and Learning (\#FSLT14) http://vle.openbrookes.net/course/view.php?id=11 and Teaching Online Open Course (\#TOOC14) http://vle.openbrookes.net/course/view.php?id=12. Consequently, both students could access this alongside their roles as teaching assistants and were enabled to combine their participation in the OOCs within their learning contracts and were each credited with a postgraduate Independent Study Module.

\section{How the Teaching Assistant role worked in practice}

One of the students was assigned as teaching assistant to an evidence-based practice module and the other student to a research methods module. This was very much in keeping with their respective professional backgrounds as a Practice Development Nurse in the US and a Senior Clinical Research Nurse in the UK NHS.

\section{Reflection upon the TA role}

The TAs negotiated their roles within the respective module team. Initially, the roles were planned as supporting the online discussion forums and real-time classrooms, in addition to taking responsibility for updating a selected learning unit (including the development of resources such as relevant podcasts and videos). It became quite apparent in both cases that the TAs developed key dialogic relationships with students on the modules and were able to offer new or alternative perspectives to those of the module tutors about learning within the individual modules (e.g. when learners felt that there was insufficient information about how to prepare for the formative assignment). One of the TAs developed a resource related to approaching a formative assignment as an online distance learning student. The outcome fits very well with Boyer's concept (Kenny, 1998) of 'student as producer' and, in particular, 'Faculty collaborating with learners in common inquiry and the maximisation of the collision of ideas' (p. 16).

\section{The voice of the TAs: A reflective account}




\section{Case Studies}

\section{Implementation of the TA role}

We TAs assumed this role with some clear goals in mind. Our primary objective for the TA role was to support the teaching team in delivery to postgraduate students of an effective module. Additional aims included: to gain insight into the experience of performing a TA role whilst sharing our personal strategies as effective distance learners; to demonstrate continued academic and professional growth during the course of postgraduate study; to combine our academic, professional and practical experiences to connect with students in a manner unique to the TA role; to avail ourselves of opportunities and experiences emerging from a new and innovative role.

Despite our enthusiasm for and willingness to take on the TA role, we had some initial concerns as to whether our student peers would readily regard us in this capacity. Some students on our assigned modules had been with us throughout our two-year learning journey, but many were unknown to us. The early insecurities and inhibitions we experienced were soon forgotten as our place on the teaching team became quickly established and solidified through clear communication and consistent engagement.

\section{Module induction}

The module induction week gave us the opportunity to review the content in the first unit, identify omissions, make suggestions, review links and ask the rest of the teaching team questions for clarification. We reviewed the literature and assigned reading in preparation for answering questions and supporting more reflective and collaborative discussions in the online boards. This set the precedent for unit preparation and continued throughout the module.

It proved an ideal time to introduce our role to the students participating in each module. This was a task that the teaching team executed with excellence and ease, clearly establishing our membership of the team and setting clear expectations in relation to roles and interactions. To follow this communication, we provided an overview of our professional, personal and academic lives to date, expressing our enthusiasm for and commitment to the TA role and our goal of supporting the students to optimise learning.

Early on, tutors established a private forum for the teaching team to share ideas, concerns, questions, suggestions and practical considerations, such as out-of-office times and other commitments. Skype meetings scheduled between TAs and tutors offered another platform by which to check in and identify a teaching lead and primary contact for each unit. The provision of this communication base established a sense of community and unity that gave us the assurance that we were perceived and treated as teaching peers by our team. It cannot be over-emphasised how important and effective it was to have that level of confidence and trust placed in us in our new and unproven roles.

It should be noted that, prior to our taking on this new role, we TAs had developed a rapport as peer distance learners and this virtual relationship provided us with invaluable mutual support and camaraderie as we conducted the TA role on our chosen modules. 


\section{Case Studies}

In addition, completing \#TOOC2014, an online open teaching course designed and led by the Oxford Centre for Learning and Staff Development (OCSLD) provided us with an extensive understanding of the challenges and merits of online teaching, its limitations and potential, and, as a result, we could effectively apply this knowledge in our TA roles.

\section{Pedagogy}

As seasoned online distance learners, we understood the value and motivation of receiving prompt recognition of and feedback on posts in the online forums. Having assumed various positions in the timely posting of assigned tasks as students, we could empathise with those leading the pack, with those unsure if they were doing it 'right', with those in the middle, with those trying to find a different perspective from the ones already posted and also with those bringing up the rear, anxious that it was too late to get feedback and engage their peers.

As outlined in Salmon's (2011) five-stage model of e-learning, regular monitoring and engaging in discussion on the student boards in the early stages of the module helps to facilitate the learning process and to modify the approach to learners based on those frequent interactions. This provides a deep source of learning for us as TAs: revisiting concepts and theories of previously completed modules in addition to responding to new and fresh perspectives from student professionals with rich experience and definite points of view.

Daily interactivity helped us to identify those students who had a difficult time navigating content and understanding what was expected of them. Wearing our dual hats, we could readily reach those students who appeared to struggle early on, understanding how overwhelming the early learning experience can be. In some instances, expressing that commonality provided students with the support they required, rather than reiterating instructions or tasks.

Having to assume a more appraising perspective when providing feedback, and encouraging deeper discussion and critical reflection on the student discussion boards, required tapping into our professional and personal selves. As working professionals undertaking postgraduate study, we possess a lot of experience in the development of process and products, which require effective collaboration with multi-disciplinary teams and administrators - skills not necessarily maximised in our student roles. Developing efficiencies of process, with straightforward guides to standardise, streamline and simplify those processes, is a reality of our working lives. With the championing and support of the teaching team and swift positive feedback from our student peers, we could apply our professional lens, in combination with our student and TA experiences, to our virtual teaching environment and develop a number of student guides (which can be reviewed in greater detail in Table 1). The amalgamation of these skill sets serves to remind us of the potential of post-graduate students and the powerful, though untapped, resource that they constitute: many of them are eager to share and collaborate when presented with the appropriate opportunity and platform. It is our experience that engaging multiple facets of our workplace, student and TA experiences provided us with a unique approach to this role. Furthermore, it promoted greater confidence in our ability to create and innovate as TAs, in addition to producing ourselves comprehensive and well-received final assignments. 


\section{Case Studies}

We both felt benefits in terms of increased teaching ability, using a different platform from any we had previously experienced; our self-confidence as online teachers improved enormously. That we both as a result felt an increased passion for teaching was interesting, as we already had face-to-face teaching experience within and outside our professional roles. We felt valued and appreciated and enjoyed a boost in confidence from being able to add this experience to our curricula vitae.

\section{Student as producer}

Developing guides based on our experience, expertise and available evidence has provided us with an unexpected and welcome source of learning. Although these guides are primarily intended to support student learning, they reinforce our own knowledge and perspectives and have the potential for use beyond the modules from which they originate.

Table 1. Guides developed by the TAs to support student learning

\begin{tabular}{|l|l|l|}
\hline Title & Purpose & Available at: \\
\hline $\begin{array}{l}\text { Guide to setting up } \\
\text { and using Google } \\
\text { Docs }\end{array}$ & $\begin{array}{l}\text { Google Docs is a free, web- } \\
\text { based office suite offered by } \\
\text { Google within its Google } \\
\text { Drive service. It allows users } \\
\text { to create and edit } \\
\text { documents online while } \\
\text { collaborating live with other } \\
\text { users. A stepwise guide for } \\
\text { students outlines how to set } \\
\text { up, use and maintain google } \\
\text { docs for writing, critical } \\
\text { reflection, tracking and } \\
\text { drafting academic work. }\end{array}$ & wwom/GoogleDocsSetup \\
\hline $\begin{array}{l}\text { Guide to developing } \\
\text { formative } \\
\text { assignments }\end{array}$ & $\begin{array}{l}\text { For some, it can be helpful } \\
\text { to have a framework by } \\
\text { which to develop formative } \\
\text { assignments, laying a solid } \\
\text { foundation for final } \\
\text { summative assignments. A } \\
\text { series of questions in this } \\
\text { guide helps to signpost } \\
\text { assignment development in } \\
\text { keeping with the objective } \\
\text { and aims of the assignment; } \\
\text { nearly as importantly, it } \\
\text { often highlights gaps to be } \\
\text { filled. }\end{array}$ & \\
\hline $\begin{array}{l}\text { Develop Online Study } \\
\text { Skills Guide }\end{array}$ & $\begin{array}{l}\text { Adapted from Roper (2007), } \\
\text { with practical advice on how } \\
\text { to prepare self, space and } \\
\text { community for successful } \\
\text { online study. }\end{array}$ & www.tinyurl.com/DevOnlineStudySkills \\
\hline
\end{tabular}




\begin{tabular}{|l|l|l|}
\hline $\begin{array}{l}\text { "Virtual Survival": A } \\
\text { practical guide to } \\
\text { surviving and thriving } \\
\text { in the online learning } \\
\text { environment as a } \\
\text { distance learner. }\end{array}$ & $\begin{array}{l}\text { A user-friendly, practical } \\
\text { guide to help students } \\
\text { succeed in their online } \\
\text { studies, this served as part } \\
\text { of a final assignment } \\
\text { submission and will be } \\
\text { offered to MSc postgraduate } \\
\text { students as a study guide. }\end{array}$ & \\
& \\
\hline $\begin{array}{l}\text { A guide to developing } \\
\text { a research protocol } \\
\text { for post-graduate } \\
\text { students and clinical } \\
\text { researchers who wish } \\
\text { to undertake an } \\
\text { observational } \\
\text { research study based } \\
\text { within the NHS }\end{array}$ & $\begin{array}{l}\text { Students and new } \\
\text { researchers wishing to } \\
\text { undertake research within } \\
\text { the NHS need to be aware } \\
\text { of the expectations, } \\
\text { standards, and approvals } \\
\text { required. A blog was } \\
\text { created providing a step-by- } \\
\text { step guide to protocol } \\
\text { design. }\end{array}$ & \\
\hline
\end{tabular}

The approach to this pilot has been collaborative in the production of functional guides for students and in bridging the student-tutor communication gap. This gap can be attributed to a variety of reasons, including initial student trepidation about virtual engagement (Salmon, 2011), students' poor past experience of engaging with tutors and lack of online etiquette (netiquette) to empower students to communicate freely and effectively within an agreed standard of conduct. The TA role, in our experience, provides students with the additional 'link' to the teaching team to promote comfort and confidence in posting and participating in online discussions.

Although some Masters level students present with deep experience and expertise (Jameson et al, 2012), this is not always the case. Many post-graduate students possess varied degrees of clinical and academic experience and this, combined with the nature of our teaching platform, which invites cultural and language diversity, presents us TAs with the challenge of modifying our approach to learners according to their individual situation and goals. For example, in our own practice settings, we have access to academics, researchers, senior clinicians and an established administrative process to identify and resolve problems and advance that knowledge across disciplines. To deal with situations in which students do not have such an infrastructure (or, indeed, are new to their profession) requires a comprehensive understanding of the module outcomes and how that knowledge can be applied fruitfully in individual and diverse contexts. It is rewarding and humbling to find a common denominator, be that a student guide or an engaging and mutually valuable interaction with individuals on the discussion boards.

As discussed, we bring extensive nursing, evidence-based practice and research experience as TAs, and, with these, the ability to influence student experience and outcomes, consistently and effectively facilitating student questions and discussions and understanding when to lead and when to advise.

\section{Feedback on the TA role}




\section{Case Studies}

Obtaining feedback from the students after completion of the modules indicated that the students were very satisfied with the TA role. The University utilises a standard anonymous survey system that, for our modules, included a question designed to extract specific information about the TA role. Eleven students provided responses to the question:

"Can you tell us about your experience of the student teaching assistant role as a component of the teaching team?"

Thematic analysis of student responses to the TA role is outlined in Table 2, seeking to examine and record patterns and themes within the data, and subsequently grouped in terms of positive impact. The analysis was performed by the TAs then reviewed and agreed by the tutors.

Table 2. Student feedback themes

\begin{tabular}{|c|c|}
\hline Theme & Feedback \\
\hline $\begin{array}{l}\text { Increased } \\
\text { support }\end{array}$ & $\begin{array}{l}\text { Students repeatedly reported enhanced communication and learning, owing to the } \\
\text { increased support they received. }\end{array}$ \\
\hline Access & $\begin{array}{l}\text { There were reports of easier access to the teaching team and quick responses to } \\
\text { queries, which students had not consistently experienced previously. }\end{array}$ \\
\hline Relatedness & $\begin{array}{l}\text { Students reported a positive relationship between the TAs, students and tutors. } \\
\text { Particularly noted was the sharing of experiences of the TAs who had undertaken } \\
\text { those modules themselves - students felt the TAs understood their concerns and } \\
\text { related well to them. }\end{array}$ \\
\hline Belief & $\begin{array}{l}\text { The students reported a real belief in the TAs' ability to perform the role. They } \\
\text { reported enhanced confidence in the role thanks to their understanding of the } \\
\text { professional background and experience of the TAs. }\end{array}$ \\
\hline $\begin{array}{l}\text { Broadened } \\
\text { learning } \\
\text { experience }\end{array}$ & $\begin{array}{l}\text { Students suggested it was effective having someone in the teaching team with } \\
\text { current clinical experience on the taught subjects. }\end{array}$ \\
\hline Bridging the gap & $\begin{array}{l}\text { In some circumstances, some students reported an easier rapport with the TAs } \\
\text { than with the tutors, which, overall, had a positive impact on their communication } \\
\text { with the teaching team. }\end{array}$ \\
\hline
\end{tabular}

When the expectations of the teacher match those of the student, the stage is set for effective learning; both student and teacher benefit in a variety of ways: closer communication, better grades, an increased sense of community and a higher degree of satisfaction. Our experience has shown that TAs can: assist in bridging potential studentteacher communication gaps; support students' learning through sharing professional knowledge (and student experience); enhance, in parallel, their own teaching delivery skills and knowledge. 


\section{Case Studies}

\section{Voice of the tutors}

\section{Tutor perspective}

The original aims of the project from a tutor perspective were to increase social and cognitive presence and promote constructive alignment of the ongoing curriculum, using the model of student as producer. Although the TAs were supervised, the benefits of having them as additional team members during the teaching process are unequivocal. Team presence in online discussion forums was greater than it otherwise would have been and student queries were answered promptly.

The greatest contribution of the TAs is that they help to break down traditional barriers between tutors and students. The dual tutorial role of teaching and assessment may result in students' being hesitant to ask questions or raise issues, but students appear to have identified with the TAs to an extent, resulting in increased interaction and more open communication. This facilitated greater engagement and debate, particularly in the research methods module, which historically has presented many students with troublesome areas of knowledge. It appeared that higher levels of communication and openness between students and teaching team bridged a gap that had been notable on previous module runs.

Miyazoe and Anderson (2013) suggest application of Anderson's (2003) Interaction Equivalency Theory to the evaluation of online courses. The theory identifies six dimensions of interaction which are learner-content, learner-teacher, learner-learner, teacher-content, teacher-teacher and content-content. There are two underlying premises. Firstly, one of the three learner dimensions needs to be high in order to achieve a quality learning experience. On our evaluation of the TA role, all three learner dimensions were high, but of course this does bring resource implications, which is the second premise of the theory and a consideration for the future.

A problematic aspect of the breaking down of barriers was that TAs were often asked the more difficult questions about assessment and content. This could pose a challenge to some beginners in postgraduate teaching. The TAs also had to learn to set some boundaries to the extent of help offered. For example, the tutors advised against reviewing drafts of other students' coursework for them (outside the confines of existing formative assignment arrangements), as this service is not on offer from staff tutors.

The success of TAs in these two modules relied on the commitment of the TAs and - to a lesser extent - of the tutors. Care was taken to offer the TAs support when they requested it and, as a quality assurance measure, tutors read the material posted by TAs in forums. TAs also received regular supervision contact. The enthusiasm and professionalism of the TAs meant that surveillance was not required. However, this might have been different with different TAs, less secure in their role, less experienced or less committed. Poor quality teaching by TAs was not an issue here, but it could unravel similar projects. Both TAs had professional attributes, skills and knowledge as experienced specialist nurses in their own right, which was beneficial in terms of reviewing and updating the ongoing curriculum and interpersonal skills to recognise cues from learners and promote interactivity. This is congruent with our notion of student as producer. Healey et al. (2014) have identified four areas for future and continuing partnership working with learners and this pilot applies directly to one of these areas which focuses upon learning, teaching and assessment. 


\section{Case Studies}

\section{Recommendations for future research and practice}

There is much research demonstrating that the successful online student is self-directed, independent, personally responsible for her/his learning and possesses self-confidence, competence, proficient reading, writing and comprehension skills and, critically, a strong desire or motivation to learn (JISC, 2009 and Sharpe, 2014). These traits are congruent with those that were required for us effectively to execute our role and are reflected in core attributes identified for Oxford Brookes graduates.

Professional teachers are discovering allies among their students, as the possibilities and effectiveness of students' teaching peers, younger students and adults are becoming increasingly evident. The phenomenon of student as producer is one that should be dynamic, continuously evolving and adapting, based on contributor, content, environment, audience, experience and motivation. Table 3 outlines our recommendations with regard to future research and practice. While these recommendations are developed with our local environment in mind, they may be applied more broadly in settings that have comparable infrastructure and TA leadership in place.

Table 3. TA future practice recommendations

\section{Recommendations for future practice}

There is opportunity for other module leaders to adopt the role of TA as part of the teaching team and with it to gain the valuable lessons and guides produced by this pilot, in addition to unique insight into their own modules.

Consider the value of TA-produced materials beyond the modules during which they were developed (such as those outlined in Table 2, which are relevant for many postgraduate students across multiple disciplines) and how they may be made accessible.

Integrating TAs with the teaching team creates an opportunity to consider resource allocation of tutor contact hours while continuing to provide high-quality student experience (Lincoln, 2005).

Identification, recruitment and preparation of students for a TA role beyond a pilot phase will require collaboration and investment by university leadership, module leaders and the pioneers leading the effort.

Consideration as to how to manage feedback should be undertaken by universities, in conjunction with the student TA.

Table 4. TA future research recommendations

Recommendations for future research:

Can the successful integration of the TA into the teaching team facilitate teaching larger numbers of students by subject type while maintaining high-quality experience and learning outcomes?

Can we develop a framework by which to identify, recruit, train and support TAs to participate as effective and satisfied members of the teaching team?

How might the TAs be surveyed, the better to understand what works well and what needs to be improved, to optimise their experience and contributions beyond this pilot?

What type of environment will continually foster creativity and innovation in online learning, enabling students to self-identify for TA and other collaborative, knowledge-sharing opportunities? 
Future research into fostering partnership working environments, creativity and innovation, resulting in students' being interested in taking on the TA role, perhaps with extension to PhD students.

\section{Conclusion}

As we review our goals for the TA role, it is clear that the primary objective of effectively supporting the teaching team in delivery of a high-quality module was achieved. Our aims to optimise our unique perspective as experienced distance learners, TAs and working professionals not only served to enrich the experience of the students throughout the taught module, but resulted in practical, evidence-based, documented guides that will continue to add value and support to future learners both locally and more broadly, if adopted beyond the modules from which they originated.

We have learned that the role of student as producer is a resource which, when aligned with effective leadership and a solid infrastructure within which to function, can collaborate, enhance, innovate and produce, providing insight and previously untapped expertise, while concurrently maintaining a successful student role and meeting learning outcomes and requirements.

The extent of opportunities arising from the performance of this role has not yet been fully realised, but the enthusiasm and willingness to persist is perfectly apparent. Time will tell.

The impact of the role on both the students undertaking the TA role and the tutors was profound. Student experience was enhanced as a result of addressing previous gaps in communication and links to the teaching teams, which enabled a positive online community during the modules. Post-graduate students have extensive knowledge in their own professional right and, we argue, have been a previously untapped resource for higher education Masters level degrees.

\section{Reference list}

Anderson, T. (2003) Getting the Mix Right Again: An Updated and Theoretical Rationale for Interaction. The International Review Of Research In Open And Distance Learning, 4(2). Available at: http://www.irrodl.org/index.php/irrodl/article/view/149/230 (Accessed: 15 September 2014).

Briggs, S. (2013) 50 Reasons Why Online Learning Deserves Respect. InformED. Available at: http://www.opencolleges.edu.au/informed/features/50-reasons-online-learning-deservesrespect/ [Accessed 4 August 2014].

Jameson, J. Jones, M. and Strudwich, K. (2012) Browne, employability and the rhetoric of choice: student as producer and the sustainability of HE. Enhancing Learning in the Social Sciences. 4(3). Available at: http://journals.heacademy.ac.uk/doi/abs/10.11120/elss.2012.04030006 (Accessed: 15 September 2014).

JISC (2009). Effective Practice in a Digital Age, JISC. UK.

Kenny, R., (1998) Reinventing Undergraduate Education: A Blueprint for America's Research Universities., Stony Brook University: the Boyer Commission on Educating 


\section{Case Studies}

Undergraduates in the Research University. Available at:

http://www.niu.edu/engagedlearning/research/pdfs/Boyer Report.pdf. (Accessed: 12

September 2015).

Miyazoe, T. \& Anderson, T. (2013) Interaction Equivalency in an OER, MOOCS and Informal Learning Era. Journal of Interactive Media in Education. Available at:

http://jime.open.ac.uk/jime/article/view/2013-09 (Accessed: 16 October 2013).

Neary, M. and Winn, J. (2009) The Student as Producer: reinventing the student experience in higher education. In: The future of higher education: policy, pedagogy and the student experience. Continuum, London.

Oxford Brookes University (2014) Strategy For Enhancing The Student Experience 2 (20152020). Oxford. Oxford Brookes University. Available at:

https://www.brookes.ac.uk/services/ocsld/sese/sese2 2015-20.pdf (Accessed: 5 October 2014).

Roper, A. R. (2007). 'How students develop online learning skills.' EDUCAUSE Quarterly Magazine. Available at:

https://net.educause.edu/ir/library/pdf/EQM07110.pdf (Accessed: 14 September 2014).

Salmon, G. (2011) E-moderating: The key to teaching and learning online (3rd ed.). New York: Routledge.

Sharpe, R. (2014) 'What Does it Take to Learn in Next Generation Learning Spaces?' In: Kym Fraser (Ed.) The Future of Learning and Teaching in Next Generation Learning Spaces (International Perspectives on Higher Education Research, Volume 12). Emerald Group Publishing Limited 123-146. 